\title{
Gamma and proton irradiation effects and thermal stability of electrical characteristics of metal-oxide-silicon capacitors with atomic layer deposited $\mathrm{Al}_{2} \mathrm{O}_{3}$ dielectric
}

J.M. Rafi $^{1{ }^{*}}$, G. Pellegrini ${ }^{1}$, V. Fadeyev ${ }^{2}$, Z. Galloway ${ }^{2}$, H.F.-W. Sadrozinski ${ }^{2}$, M. Christophersen ${ }^{3}$, B.F. Phlips ${ }^{3}$, D. Lynn ${ }^{4}$, J. Kierstead ${ }^{4}$, M. Hoeferkamp ${ }^{5}$, I. Gorelov ${ }^{5}$, P. Palni ${ }^{5}$, R. Wang ${ }^{5}$, S. Seidel ${ }^{5}$

${ }^{1}$ Institut de Microelectrònica de Barcelona, IMB-CNM, (CSIC), Campus UAB, 08193 Bellaterra, Spain

${ }^{2}$ Santa Cruz Institute for Particle Physics, University of California, Santa Cruz, CA, USA ${ }^{3}$ U.S. Naval Research Laboratory, Washington DC, USA

${ }^{4}$ Physics Dept., Brookhaven National Laboratory, Upton, NY, USA

${ }^{5}$ Dept. of Physics and Astronomy, Univ. of New Mexico, Albuquerque, NM, USA

*Corresponding author. Tel.: +34 93 5947700, ext.: 2201

Electronic mail: jm.rafi@csic.es 


\section{ABSTRACT}

The radiation hardness and thermal stability of the electrical characteristics of atomic layer deposited $\mathrm{Al}_{2} \mathrm{O}_{3}$ layers to be used as passivation films for silicon radiation detectors with slim edges are investigated. To directly measure the interface charge and to evaluate its change with the ionizing dose, metal-oxide-silicon (MOS) capacitors implementing differently processed $\mathrm{Al}_{2} \mathrm{O}_{3}$ layers were fabricated on p-type silicon substrates. Qualitatively similar results are obtained for degradation of capacitance-voltage and current-voltage characteristics under gamma and proton irradiations up to equivalent doses of $30 \mathrm{Mrad}$ and 21.07 Mrad, respectively. While similar negative charge densities are initially extracted for all non-irradiated capacitors, superior radiation hardness is obtained for MOS structures with alumina layers grown with $\mathrm{H}_{2} \mathrm{O}$ instead of $\mathrm{O}_{3}$ as oxidant precursor. Competing effects between radiation-induced positive charge trapping and hydrogen release from the $\mathrm{H}_{2} \mathrm{O}$ grown $\mathrm{Al}_{2} \mathrm{O}_{3}$ layers may explain their higher radiation resistance. Finally, irradiated and nonirradiated MOS capacitors with differently processed $\mathrm{Al}_{2} \mathrm{O}_{3}$ layers have been subjected to thermal treatments in air at temperatures ranging between $100^{\circ} \mathrm{C}$ and $200^{\circ} \mathrm{C}$ and the thermal stability of their electrical characteristics has been evaluated. Partial recovery of the gamma-induced degradation has been noticed for $\mathrm{O}_{3}$-grown MOS structures. This can be explained by a trapped holes emission process, for which an activation energy of $1.38 \pm 0.15$ eV has been extracted.

Keywords: $\mathrm{Al}_{2} \mathrm{O}_{3}$; $\mathrm{ALD}$; gamma irradiation; proton irradiation; irradiation effects; thermal stability 


\section{INTRODUCTION}

In recent years, a number of high permittivity (high-k) dielectrics have been investigated for a wide range of micro/nanotechnology applications, $\mathrm{Al}_{2} \mathrm{O}_{3}$ being amongst the most studied ones $[1,2]$. The requirements of large area uniformity, conformality, accurate thickness control of the dielectric layers and low-temperature budget can be achieved by means of atomic layer deposition (ALD) technique. Interestingly, as a difference to other conventional thermally grown or deposited dielectrics like $\mathrm{SiO}_{2}$ and $\mathrm{Si}_{3} \mathrm{~N}_{4}$, for which positive fixed charge densities are generally obtained, intrinsic negative charges are found for $\mathrm{ALD}^{\mathrm{Al}} \mathrm{O}_{3}$ films [3]. The ultimate origin of the negative charges in $\mathrm{Al}_{2} \mathrm{O}_{3}$ films is still under debate, however, it has been pointed that aluminum vacancies and oxygen interstitials produce levels in the lower half of $\mathrm{Al}_{2} \mathrm{O}_{3}$ bandgap, which are candidates to trap negative charges $[4,5]$. These defect states may be charged by electron tunneling from Si substrate into $\mathrm{Al}_{2} \mathrm{O}_{3}$. It has been demonstrated that the presence of a $\mathrm{SiO}_{2}$ interlayer between $\mathrm{Si}$ and $\mathrm{Al}_{2} \mathrm{O}_{3}$ plays a key role in negative charge formation. An increase in $\mathrm{SiO}_{2}$ interlayer thickness is known to decrease the effective negative charge densities, eventually leading to positive charge densities for $\mathrm{SiO}_{2}$ interlayer thicknesses in the range of $5 \mathrm{~nm}$ to $10 \mathrm{~nm}$ [6]. This has been attributed to a reduction of tunnelling of electrons into $\mathrm{SiO}_{2} / \mathrm{Al}_{2} \mathrm{O}_{3}$ negative traps, as well as to the introduction of fixed and bulk positive charges at the $\mathrm{Si} / \mathrm{SiO}_{2}$ interface and $\mathrm{SiO}_{2}$, respectively $[6]$.

In the last years, excellent surface passivation properties for $\mathrm{Al}_{2} \mathrm{O}_{3}$ layers on high-efficiency crystalline silicon solar cells have been proven by a considerable number of studies $[7,8]$. Passivation is partly attributed to the electric field induced by the negative charges, which 
repels charge carriers from the silicon cell surface, thus avoiding their recombination [3]. Additionally, a chemical passivation mechanism is associated with the reduction of surface recombination by a low $\mathrm{Si} / \mathrm{Al}_{2} \mathrm{O}_{3}$ interface defect density [5]. Optimal passivation results have been obtained for $\mathrm{Al}_{2} \mathrm{O}_{3}$ layers with thicknesses typically in the range of 20-30 nm $[3,5,7]$, while lower properties have been appreciated for thinner layers $(<10 \mathrm{~nm})$, what has been attributed to a reduced passivation at the $\mathrm{Si} / \mathrm{Al}_{2} \mathrm{O}_{3}$ interface [5].

More recently, in the field of silicon tracking detectors for high-energy physics experiments, interest has also arisen for $\mathrm{ALD} \mathrm{Al}_{2} \mathrm{O}_{3}$ passivation layers. Silicon tracking detectors are key sub-systems of any modern particle physics experiment. They provide charge particle tracking with high spatial resolution, and are capable of operating in harsh radiation environments $[9,10]$. Building a full size system in a large experiment, such as ATLAS [11] and CMS at CERN, is a challenging endeavour, due to the practical aspects of instrumenting large area with hermetic coverage. Typically sensors contain inactive regions at their periphery, which requires either tiling them to achieve the hermeticity, or introduction of additional layers to compensate for the acceptance gaps. There are similar requirements in other fields (e.g. medical imaging) that would benefit from maximizing sensor's active area fraction. As a part of the ATLAS Upgrade R\&D, we are developing technologies for minimizing the inactive area at the periphery of the sensors, so called "slim edge" approach, to enable hermetic tiling of sensors into large instrumented areas. The method of choice in our investigation is scribe-cleave-passivate (SCP) [12]. Scribing and cleaving steps result in high surface quality on the sidewall, with low defect density $[13,14]$. The passivation with proper interface charge repels the carriers from the sidewall effectively achieving a resistive surface [15]. This is analogous to the voltage drop along the top surface in the guard ring 
region of a single-sided sensor, where a certain distance is required to sustain a given bias voltage [16]. In the SCP method the sidewall takes the role of the top region allowing the voltage gradient on its surface. For $p$-type bulk devices we need to use alumina $\left(\mathrm{Al}_{2} \mathrm{O}_{3}\right)$ to passivate the sidewall and to provide negative interface charge with silicon, so that minority charge carriers are repelled and surface recombination is reduced. Radiation tests on such devices indicated relatively low radiation resistance for low fluences [17] with protons, but not with neutrons, indicating possible surface damage.

In recent years, a lot of work has been devoted to physical and electrical characterization of high-k dielectrics, as well as to reliability issues [18]. However, much less is known about their behaviour in radiation environments. Different works have been published on radiation effects on a limited number of high-k dielectrics, with $\mathrm{Al}_{2} \mathrm{O}_{3}$ amongst them [19-22]. However, these have been mostly limited to irradiations with X-rays, electrons or heavy ions, and separated studies addressing either capacitance-voltage (C-V) or current-voltage (I-V) characterization have been generally considered. Moreover, little is known about annealing of radiation-induced damage in $\mathrm{ALD} \mathrm{Al}_{2} \mathrm{O}_{3}$ dielectric films [23], the thermal stability of their electrical characteristics being of particular interest.

In this work, we are specifically addressing the radiation hardness of the alumina layer with ionizing radiation. To directly measure the interface charge and to evaluate its change with the ionizing dose, we manufactured Metal-Oxide-Silicon (MOS) capacitors. We varied some details of the $\mathrm{Al}_{2} \mathrm{O}_{3}$ layers processing sequence, including the use of $\mathrm{H}_{2} \mathrm{O}$ or $\mathrm{O}_{3}$ as oxidant precursors, film thickness and post-processing annealing. We then irradiated the different sample categories with gammas and protons and studied the effects on the electrical 
characteristics, as well as their thermal stability. The results indicate that some of the processing variations can produce radiation-hard alumina layers.

\section{EXPERIMENTAL DETAILS}

\section{1. $\mathrm{Al}_{2} \mathrm{O}_{3} \mathrm{MOS}$ capacitors fabrication}

MOS capacitors were fabricated in Centro Nacional de Microelectrónica (CNM) cleanroom on four 100 mm-diameter (100)-oriented Czochralski-grown p-type silicon wafers with 0.1$1.4 \Omega \cdot \mathrm{cm}$ resistivity. After cleaning in $\mathrm{H}_{2} \mathrm{O}_{2} / \mathrm{H}_{2} \mathrm{SO}_{4}$ and a dip in $\mathrm{HF}(5 \%)$, a wet thermal oxidation process at $1100 \stackrel{\circ}{\circ}$ in a quartz tube furnace resulted in a $400 \mathrm{~nm}$-thick $\mathrm{SiO}_{2}$ layer, which was patterned by photolithography and wet etching. In order to investigate any possible process-related radiation hardness differences, blanket $\mathrm{Al}_{2} \mathrm{O}_{3}$ dielectric layers with nominal thickness of $20 \mathrm{~nm}$ and $40 \mathrm{~nm}$ were deposited by ALD in two different facilities, CNM and U.S. Naval Research Laboratory (NRL) (Table 1).

Deposition of $\mathrm{CNM} \mathrm{Al} \mathrm{O}_{3}$ layers was carried out immediately after cleaning in $\mathrm{H}_{2} \mathrm{O}_{2} / \mathrm{H}_{2} \mathrm{SO}_{4}$ and a dip in HF (5\%). The films were deposited at $250^{\circ} \mathrm{C}$ in a Cambridge NanoTech Savannah 200 system, by using trimethylaluminium (TMA) and $\mathrm{O}_{3}$ as precursors, and $\mathrm{N}_{2}$ as carrier and purge gas. For $\mathrm{CNM}$ layers $\mathrm{O}_{3}$ was chosen as oxidant precursor, so as to reduce possible blistering phenomena. $\mathrm{Al}_{2} \mathrm{O}_{3}$ layer blistering is associated with a local delamination of the film and is thought to be caused by gaseous desorption upon thermal treatments of the ALD layers, where the dielectric films may act as a gas barrier, thus giving rise to bubble 
formation [5,24]. Blistering may be encountered for relatively thick ( $>10 \mathrm{~nm}$ ) $\mathrm{Al}_{2} \mathrm{O}_{3} \mathrm{ALD}$ layers and it has been found to be reduced when using $\mathrm{O}_{3}$ oxidant instead of $\mathrm{H}_{2} \mathrm{O}$ [25].

For the case of NRL samples, an additional Silox Vapox III etch of about 20 seconds was carried out, so as to remove any possible native oxide formed during handling and shipping of the wafers from CNM to NRL. Subsequently, ALD was quickly performed (within 1 minute,

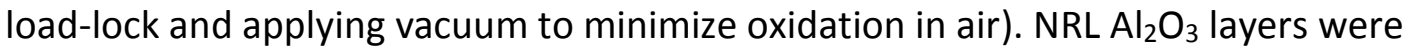
deposited at $300^{\circ} \mathrm{C}$ in an Oxford Plasma ALD system, by using trimethylaluminium (TMA) and $\mathrm{H}_{2} \mathrm{O}$ as precursors, and $\mathrm{N}_{2}$ as carrier and purge gas. A post-deposition anneal (PDA) treatment of 10 minutes at $300^{\circ} \mathrm{C}$ in $\mathrm{H}_{2}$ atmosphere was carried out for NRL wafers, just after ALD.

The $\mathrm{Al}_{2} \mathrm{O}_{3}$ film thickness was measured prior to gate formation by means of a Rudolph Research Auto EL Ellipsometer, using an index of refraction of 1.64, as well as by a Nanometrics Nanospec 6100 interferometer. The obtained physical thickness values are given in Table 1. A $500 \mathrm{~nm}$-thick Al (99.5\%)/Cu (0.5\%) layer was deposited as the metal gate of the MOS capacitors. After patterning the metal layer by photolithography and wet etching, the back of the wafers was fully metalized with a $500 \mathrm{~nm}$-thick Al layer for electrically contacting the silicon substrate. Finally, the wafers were cut into halves and one half underwent a forming gas $\left(\mathrm{N}_{2} /(10 \%) \mathrm{H}_{2}\right)$ post-metallization annealing (PMA) step at 350 oC for 30 minutes. The fabricated MOS capacitors are square-shaped with five different surface areas (A) ranging from $9.6 \times 10^{-3} \mathrm{~cm}^{2}$ to $6.4 \times 10^{-5} \mathrm{~cm}^{2}$. No blistering phenomena were observed on neither CNM nor NRL $\mathrm{Al}_{2} \mathrm{O}_{3}$ MOS capacitors subjected or not to the PMA 
treatment. If the contrary is not indicated, MOS structures with $2.3 \times 10^{-3} \mathrm{~cm}^{2}$ and $6.4 \times 10^{-5}$ $\mathrm{cm}^{2}$ areas were used for $\mathrm{C}-\mathrm{V}$ and I-V measurements, respectively.

\subsection{Irradiation and electrical characterization}

MOS capacitors were subjected to unbiased gamma and proton irradiations (the gates of capacitors were left floating) at room temperature. While gamma irradiations were carried out at Brookhaven National Laboratory for six different doses (0.1 Mrad, 0.3 Mrad, 1 Mrad, $3 \mathrm{Mrad}, 10 \mathrm{Mrad}$ and $30 \mathrm{Mrad}$ ), $800 \mathrm{MeV}$ proton irradiations were performed in Los Alamos National Laboratory for six different fluences $\left(1.39 \times 10^{12} \mathrm{p} / \mathrm{cm}^{2}, 6.94 \times 10^{12} \mathrm{p} / \mathrm{cm}^{2}, 1.92 \times 10^{13}\right.$ $\mathrm{p} / \mathrm{cm}^{2}, 7.93 \times 10^{13} \mathrm{p} / \mathrm{cm}^{2}, 1.47 \times 10^{14} \mathrm{p} / \mathrm{cm}^{2}$ and $\left.6.84 \times 10^{14} \mathrm{p} / \mathrm{cm}^{2}\right)$, with corresponding equivalent doses in the range of the gamma irradiations ( $0.043 \mathrm{Mrad}, 0.214 \mathrm{Mrad}, 0.591$ Mrad, 2.44 Mrad, 4.53 Mrad and 21.07 Mrad). The equivalent total ionization dose (TID) has been computed according to tables of proton stopping power in silicon maintained by NIST [26].

Capacitance-voltage (C-V) and current-voltage (I-V) characteristics were measured using an HP-4192 A LF impedance analyzer and an HP 4155B semiconductor parameter analyser, respectively. C-V measurements were performed at a signal frequency (f) of $100 \mathrm{kHz}$ for both, inversion to accumulation and accumulation to inversion voltage sweeps. The capacitance of the MOS structures in accumulation regime was assumed as the oxide capacitance $\left(C_{o x}\right)$ and it was used to estimate the equivalent oxide thickness (EOT) of the dielectric layers. The hysteresis was defined as the difference between the extracted flat- 
band voltages $\left(\mathrm{V}_{\mathrm{fb}}\right)$ corresponding to the two voltage sweeps $\left(\mathrm{V}_{\mathrm{hys}}=\mathrm{V}_{\mathrm{fb} \_ \text {inv_to_acc }} \mathrm{V}_{\mathrm{fb} \_ \text {acc_to_inv }}\right)$. An estimation of the effective trapped charge density ( $\left.N_{\text {eff }}\right)$, defined as a charge located at the silicon/insulator interface, was obtained from the comparison between the extracted $V_{\mathrm{fb}}$ values and the ones expected for an ideal MOS structure with $4.25 \mathrm{eV}$ metal work function, corresponding to the aluminium gate electrode. The conductance versus voltage (G-V) characteristics were also recorded. An estimation of the interface states density ( $\left.D_{i t}\right)$ was obtained from the peak of the parallel conductance $\left(G_{p}\right)$ derived from the $G-V$ measurements $[27,28]$ :

$$
D_{i t} \approx \frac{2.5}{q \cdot A} \cdot \frac{G_{p}}{2 \pi f}
$$

where $q$ is the electron charge.

\section{RESULTS AND DISCUSSION}

\subsection{Non-irradiated devices}

\section{Capacitance-voltage characteristics}

Figure 1 shows an example of typical C-V characteristics measured from inversion to accumulation and accumulation to inversion for different $\mathrm{Al}_{2} \mathrm{O}_{3} \mathrm{MOS}$ capacitors corresponding to the four fabricated wafers described in Table 1. As it can be observed, significant flat band voltage differences can be appreciated between samples that received 
or did not receive a PMA treatment. Moreover, hysteresis between the curves measured with the two voltage sweeps directions can be easily appreciated for all the samples that have not been subjected to a PMA treatment. This observed counter clockwise hysteresis on p-type Si capacitors is attributed to silicon/dielectric interface and near interface border traps [29], which may get charged and exchange electrons with the silicon substrate depending on the voltage sweep direction $[27,30]$.

In agreement with previous results on thinner layers, the effect of a PMA treatment is found to decrease the density of negative effective trapped charges [31], as well as to significantly reduce $\mathrm{C}-\mathrm{V}$ hysteresis $[32,33]$ and interface states density $[22,34]$. This can be appreciated in Fig. 1 inset, where the observed peaks in the conductance characteristics are significantly reduced after the PMA treatment. Annealing out of dangling bonds at silicon/dielectric interface in such PMA hydrogen-rich ambient is believed to be responsible for the observed beneficial effects [32,34].

In the present study, a PMA has also been found to significantly reduce any wafer level variability of C-V and I-V characteristics. This can be appreciated in Table 2 results, where the most relevant electrical parameters extracted from the $\mathrm{C}-\mathrm{V}$ characterization on a set of $25 \mathrm{MOS}$ capacitors are given. As expected, negative $\mathrm{N}_{\text {eff }}$ values are obtained for all $\mathrm{Al}_{2} \mathrm{O}_{3}$ layers. Interestingly, although higher densities of negative effective trapped charges are noticed for NRL dielectric layers compared to CNM ones, the results become quite similar after a PMA treatment. These results are in agreement with previous studies where higher negative $\mathrm{N}_{\text {eff }}$ values have been obtained for $\mathrm{ALD} \mathrm{Al}_{2} \mathrm{O}_{3}$ layers grown with $\mathrm{O}_{3}$ compared to $\mathrm{H}_{2} \mathrm{O}$ as oxidant source $[31,35,36]$, which has been attributed to a higher O/Al ratio at the 
semiconductor/dielectric interface for $\mathrm{O}_{3}$-grown films, together with the fact that aluminum vacancies and oxygen interstitials are believed to introduce negative fixed charge levels within $\mathrm{Al}_{2} \mathrm{O}_{3}$ bandgap $[4,5]$. As shown in Table 2 results, and in further agreement with previous studies [36,37], the $\mathrm{N}_{\text {eff }}$ differences between $\mathrm{ALD} \mathrm{Al}_{2} \mathrm{O}_{3}$ layers grown with $\mathrm{O}_{3}$ and $\mathrm{H}_{2} \mathrm{O}$ as oxidant source diminish after the PMA thermal treatment, which may be explained in terms of an interfacial restructure [37].

From Table 2 , higher interface states density values $\left(D_{\text {it }}\right)$ are obtained before PMA for CNM dielectric layers compared to NRL ones. The higher density of dangling bonds in $\mathrm{CNM}^{-\mathrm{Al}_{2} \mathrm{O}_{3}}$ layers can be explained by a lower hydrogen contents in the layers grown with $\mathrm{O}_{3}$ compared to the ones using $\mathrm{H}_{2} \mathrm{O}$ as oxidant source $[35,37,38]$. From Table 2 results, $D_{\text {it }}$ differences between $\mathrm{O}_{3}$ and $\mathrm{H}_{2} \mathrm{O}$-grown layers diminish after the samples have been subjected to the hydrogen-rich atmosphere during the PMA treatment. This is also in agreement with some previous studies [36,37].

The extracted values for the equivalent oxide thickness (EOT) are in the range of $19.4 \mathrm{~nm}-$ $22.9 \mathrm{~nm}$ and $10.6 \mathrm{~nm}-12.3 \mathrm{~nm}$ for the $40 \mathrm{~nm}$ and $20 \mathrm{~nm}$-thick $\mathrm{Al}_{2} \mathrm{O}_{3}$ layers, respectively. $\mathrm{By}$ taking into account the measured physical thickness results of Table 1, a relative permittivity in the range of 1.9 to 2 times and 1.75 to 1.85 times the value corresponding to $\mathrm{SiO}_{2}$ is obtained for CNM and NRL layers, respectively. This is in agreement with previous values obtained on comparable MOS capacitors with thinner $(10 \mathrm{~nm}) \mathrm{ALD} \mathrm{Al}_{2} \mathrm{O}_{3}$ dielectric layers [21]. 


\section{Current-voltage characteristics}

Figure 2 shows typical current density versus applied voltage characteristics measured for $\mathrm{Al}_{2} \mathrm{O}_{3}$ MOS capacitors corresponding to the four fabricated wafers described in Table 1. As can be seen, higher conduction levels are generally observed at high voltages (with absolute values higher than about $10 \mathrm{~V}$ and $20 \mathrm{~V}$ for $20 \mathrm{~nm}$ and $40 \mathrm{~nm} \mathrm{Al} \mathrm{O}_{3}$ layers, respectively) for CNM samples compared to NRL ones. This can be partly explained by the higher thickness values obtained for $\mathrm{NRL} \mathrm{Al}_{2} \mathrm{O}_{3}$ layers compared their $\mathrm{CNM}$ counterparts, as it has been observed in Table 1 physical and Table 2 electrical results. In this high electric field region, which would correspond to values in the range of $5 \mathrm{MV} / \mathrm{cm}$ and above, no significant electrical conduction differences have been observed between samples subjected or no to the PMA treatment, until dielectric breakdown occurs, what is registered as a sudden increase in current density, reaching a pre-established current compliance level. The current-voltage characteristics in this region have been found to scale with capacitor area, thus indicating conduction through the full high-k dielectric active area.

With regard to electrical conduction mechanisms, Fowler-Nordheim (FN) tunnelling is thought to be responsible for the fixed slope region of conduction just before the dielectric breakdown events. In this sense, a good agreement is observed in Figure 2 between the measured curves and the round symbols plots corresponding to FN conduction law fitting. From these fits, reasonable FN barrier values between $2.5 \mathrm{eV}$ and $4.3 \mathrm{eV}$ have been extracted for the MOS capacitors with the different $\mathrm{Al}_{2} \mathrm{O}_{3}$ layers, by considering the effective mass of electrons in alumina as 0.2 times the free electron mass $[39,40]$. These results are in agreement with previous studies published in the literature for electrical conduction of ALD 
$\mathrm{Al}_{2} \mathrm{O}_{3}$ layers at high electric fields $[21,40-42]$. In the low accumulation voltages region of the I-V characteristics, reduced conduction and higher uniformity for the I-V curves have been observed for the samples subjected to the PMA treatment, compared to their No PMA counterparts. A study of the conduction mechanisms through thinnest (11.6 nm) Al ${ }_{2} \mathrm{O}_{3}$ layers with PMA pointed to Poole-Frenkel as the dominant conduction mechanism for this lower electric field region [21].

From Figure 2, dielectric breakdown events occurring for absolute voltages in the range of $30 \mathrm{~V}$ to $40 \mathrm{~V}$ and $15 \mathrm{~V}$ to $20 \mathrm{~V}$ could be already anticipated for MOS capacitors with $40 \mathrm{~nm}$ and $20 \mathrm{~nm}$-thick $\mathrm{Al}_{2} \mathrm{O}_{3}$ layers, respectively. In order to better evaluate the $\mathrm{Al}_{2} \mathrm{O}_{3}$ layers reliability, dielectric breakdown has been studied. For this purpose, ramped I-V characteristics of a set of 25 capacitors for each dielectric layer condition were measured and the breakdown voltages $\left(\mathrm{V}_{\mathrm{BD}}\right)$ were recorded. The cumulative breakdown distribution, $\mathrm{F}$, is defined as [43]:

$$
F\left(V_{B D}\right)=1-e^{-\left(\frac{\left|V_{B D}\right|}{\alpha}\right)^{\beta}}
$$

where $\alpha$ is the voltage at which $63 \%$ of the capacitors have broken down and $\beta$ is the Weibull slope, indicating the width of the distribution.

The extracted $\alpha$ and $\beta$ parameters from the Weibull dielectric breakdown distributions are shown in Table 2. In view of the obtained dielectric breakdown distributions, good yield and uniformity have been observed for all the studied $\mathrm{Al}_{2} \mathrm{O}_{3}$ layers. The somewhat higher $\mathrm{V}_{\mathrm{BD}}$ 
values for NRL layers compared to CNM ones can be explained by their higher thickness values. On the other hand, apart from slightly higher $V_{B D}$ values registered for $40 \mathrm{~nm} C N M$ layers with PMA compared to their no PMA counterparts, no clear impact of PMA treatment on dielectric breakdown has been observed.

\subsection{Irradiated devices}

\section{Capacitance-voltage characteristics}

Figure 3(a) shows an example of typical C-V characteristics measured from inversion to

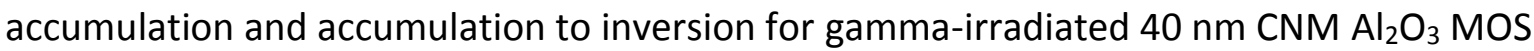
capacitors. A progressive negative shift of the curves is observed with increasing gamma irradiation dose, indicating positive charge build-up in the $\mathrm{Al}_{2} \mathrm{O}_{3}$ dielectric layer. The ionizing radiation creates electron-hole pairs in the dielectric layer and part of the low mobility holes get trapped in the oxide [19]. An estimation of the effective trapped charge density ( $\left.N_{\text {eff }}\right)$ is plotted as a function of irradiation dose in Fig. 3(b). Interestingly, a different behaviour with irradiation is observed for the samples with the $\mathrm{Al}_{2} \mathrm{O}_{3}$ layer deposited at $\mathrm{CNM}$ and $\mathrm{NRL}$ facilities. In this way, while similar negative charge densities, in the range of $-1.25 \times 10^{12} \mathrm{~cm}^{-2}$ to $-1.45 \times 10^{12} \mathrm{~cm}^{-2}$, are initially encountered for all non-irradiated capacitors, a clear radiation-induced positive charge trapping is observed for the samples with $\mathrm{CNM} \mathrm{Al}_{2} \mathrm{O}_{3}$ layers. Charge trapping rates around $0.5 \times 10^{12} \mathrm{~cm}^{-2}$ to $1 \times 10^{12} \mathrm{~cm}^{-2}$ per decade of irradiation dose can be estimated for CMM samples, what appears to be about 1.5 or 2 times slower than previous results corresponding to $2 \mathrm{MeV}$ electron irradiation on comparable $10 \mathrm{~nm}$ - 
thick $\mathrm{Al}_{2} \mathrm{O}_{3} \mathrm{CNM}$ layers [21]. It is important to note for the intended applications that positive $\mathrm{N}_{\text {eff }}$ values are finally obtained for the most irradiated capacitors with $\mathrm{CNM} \mathrm{Al}_{2} \mathrm{O}_{3}$ layers (Fig. 3(b)).

As it can be also seen in Fig. 3(b), qualitatively similar results are obtained for C-V curves degradation under equivalent doses of gamma and proton irradiations, although the obtained $\mathrm{N}_{\text {eff }}$ values are always slightly more negatives for proton irradiation.

Interestingly, no significant $\mathrm{N}_{\text {eff }}$ changes are observed for NRL dielectric layers up to doses of about 1 Mrad, thus resulting to be quite radiation-harder than their CNM counterparts. Moreover, even slightly more negative $\mathrm{N}_{\text {eff }}$ values are extracted for these samples under the highest irradiation doses. From these results, the existence of competing mechanisms in the radiation-induced degradation of NRL MOS capacitors can be envisaged. In fact, similar radiation-hardness differences were observed in the past for the case of $A L D \mathrm{HfO}_{2}$ dielectric layers with some process annealing differences and exposed to similar doses with $10 \mathrm{KeV} X$ rays [19]. Moreover, a radiation-induced passivation of interface traps was observed on similar $\mathrm{ALD} \mathrm{Al}_{2} \mathrm{O}_{3}$ layers grown with $\mathrm{H}_{2} \mathrm{O}$ oxidant, which was attributed to a beneficial effect of radiation-induced hydrogen release from the dielectric layers [44]. Our results could be explained by the competing effects between radiation-induced positive charge trapping and hydrogen release from $\mathrm{NRL} \mathrm{H}_{2} \mathrm{O}$-grown $\mathrm{Al}_{2} \mathrm{O}_{3}$ layers.

With regard to hysteresis in $\mathrm{C}-\mathrm{V}$ characteristics, and as a difference with previous results from $2 \mathrm{MeV}$ electron irradiation on thinner ( $\leq 10 \mathrm{~nm}) \mathrm{Al}_{2} \mathrm{O}_{3} \mathrm{CNM}$ layers [22], no significant changes in the magnitude of C-V curves hysteresis are appreciated here under the studied 
gamma and proton irradiations, which is in agreement with the nearly unchanged values extracted for interface states density $\left(D_{i t}\right)$. Finally, it has to be commented that no appreciable gamma or proton radiation-induced variations have been detected for semiconductor doping concentration. The extracted values from inversion region of C-V characteristics are all in the range between $2 \times 10^{16} \mathrm{~cm}^{-3}$ and $4 \times 10^{16} \mathrm{~cm}^{-3}$, and within the nominal substrate specifications range $\left(3.4 \times 10^{15} \mathrm{~cm}^{-3}\right.$ to $\left.7.8 \cdot 10^{16} \mathrm{~cm}^{-3}\right)$.

\section{Current-voltage characteristics}

Figure 4(a) shows the measured current density versus applied voltage characteristics for non-irradiated and gamma irradiated $40 \mathrm{~nm} \mathrm{CNM} \mathrm{Al} \mathrm{O}_{3} \mathrm{MOS}$ capacitors. A progressive increase of the current density through the dielectric layer is observed, thus indicating radiation-induced degradation of the $\mathrm{Al}_{2} \mathrm{O}_{3}$ film for increasing gamma irradiation dose. The degradation is relatively more important in the low electric field region of the I-V characteristics and smaller changes are appreciated in the high field slope of conduction (Fowler-Nordheim tunnelling) just before the dielectric breakdown events. These results are consistent with previous studies of $2 \mathrm{MeV}$ electron irradiation on $10 \mathrm{~nm}$-thick $\mathrm{Al}_{2} \mathrm{O}_{3} \mathrm{CNM}$ layers [21], as well as with the observed positive charge trapping from C-V characteristics. While C-V technique mainly assesses charges located near the semiconductor/dielectric interface, I-V characterization is especially sensitive to potential barrier changes near the injecting electrode [45]. As the I-V curves were measured in accumulation regime, injected electrons from the gate are expected to encounter a decreased dielectric potential barrier due to trapped positive charges near the injecting metal/dielectric interface [45]. 
Alternatively, some increase in the leakage current could be also partly explained in terms of a trap assisted tunnelling phenomenon, where the generation of traps is responsible for a radiation-induced leakage current (RILC) $[46,47]$.

Qualitatively similar results have been obtained for I-V curves degradation under equivalent doses of gamma and proton irradiations. This can be appreciated in Fig. 4(b), where the radiation-induced voltage shift of I-V characteristics at a fixed current density level of $5 \times 10^{-7}$ $\mathrm{A} / \mathrm{cm}^{2}$ has been plotted as a function of gamma and proton irradiation dose. Similarly to $\mathrm{C}-\mathrm{V}$ curves, the radiation-induced degradation of I-V characteristics is found to be much smaller for the case of NRL dielectric layers. Note also that the I-V curves shift difference between

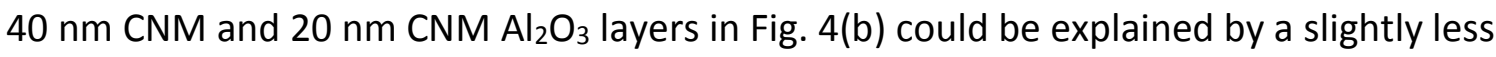
than quadratic dependence on dielectric thickness, which has been usually found for the case of threshold voltage shift of irradiated $\mathrm{SiO}_{2}$ of similar thicknesses $[19,48]$.

\subsection{Thermal stability of electrical characteristics}

The electrical stability of silicon passivation layers is of special interest for applications. Recently, beneficial effects of light soaking have been reported for $\mathrm{Al}_{2} \mathrm{O}_{3}$ passivation layers $[49,50]$. It is known from $\mathrm{SiO}_{2}$ gate dielectrics that radiation-induced defects can be detrapped or annealed by tunnel or thermal emission processes [48,51]. In order to gain better insight into the radiation-induced damage affecting the $\mathrm{Al}_{2} \mathrm{O}_{3} \mathrm{MOS}$ capacitors, a few pieces of wafers with gamma- and proton-irradiated MOS capacitors were subjected to thermal annealing treatments in air and at temperatures ranging from $100 \circ \mathrm{C}$ to $200{ }^{\circ} \mathrm{C}$. C $\mathrm{V}$ 
characteristics were measured at different stages of the thermal annealing experiments.

During the thermal anneals, the device terminals were left floating and care was taken in order to get enough cooling of the samples down to room $\mathrm{T}$ before the measurements were performed.

Interestingly, a significant recovery of the radiation-induced damage affecting the electrical characteristics was observed. This can be appreciated in Figures 5(a) and 5(b), where the extracted $\mathrm{N}_{\text {eff }}$ values from C-V are plotted as a function of thermal annealing time for some gamma and proton irradiated $40 \mathrm{~nm} \mathrm{CNM} \mathrm{Al} \mathrm{O}_{3} \mathrm{MOS}$ capacitors, respectively. The observed logarithmic dependence with annealing time is in agreement with thermal emission of radiation-induced trapped holes dominated by a spatial tunnelling process, where the probability of a hole tunnelling out of the oxide depends exponentially on the distance from the trap to the silicon/dielectric interface [51]. Although only small differences in annealing slope are appreciated at first sight in Fig. 5(a), the analysis of the time required to anneal a fixed percentage of degradation evidences an Arrhenius-law dependence on annealing temperature (inset in Fig. 5(a)) [52]. A value of $1.38 \pm 0.15 \mathrm{eV}$ for the corresponding activation energy has been extracted. This result is in the range of previous values reported in the literature for the case of thermal annealing of radiation-induced leakage currents (RILC) in conventional $\mathrm{SiO}_{2}$ gate dielectrics [53]. With regard to proton irradiated samples (Fig. 5(b)), under the studied experimental conditions, less dependence on annealing time was found, what could be attributed to a somewhat different nature or position of the damage generated with such particle irradiation compared to gamma rays. On the other hand, some small $\mathrm{N}_{\text {eff }}$ dispersion at zero annealing time between different temperature 
annealed samples is attributed to irradiation non-uniformities between the various parts of irradiated pieces used for such thermal treatments.

In light of the obtained results regarding to thermal annealing of radiation-induced damage on $40 \mathrm{~nm} \mathrm{Al} \mathrm{O}_{3} \mathrm{CNM}$ samples (Fig. 5), it is interesting to consider possible impact of thermal treatments on non-irradiated as well as irradiated $\mathrm{NRL} \mathrm{Al}_{2} \mathrm{O}_{3}$ layers. In this regard, Fig. 6(a) shows the obtained $\mathrm{N}_{\text {eff }}$ evolution as a function of thermal annealing time for some nonirradiated $40 \mathrm{~nm} \mathrm{CNM} \mathrm{Al} \mathrm{O}_{3} \mathrm{MOS}$ capacitors exposed to temperatures between $100^{\circ} \mathrm{C}$ and $200^{\circ}$ C. From Fig. $6(\mathrm{a})$, a good thermal stability of the original $\mathrm{Al}_{2} \mathrm{O}_{3}$ negative charges is observed under a $100^{\circ} \mathrm{C}$ thermal treatment. However, a significant loss of effective negative charges is appreciated for higher temperatures (175으 $\mathrm{C}$ and $\left.200^{\circ} \mathrm{C}\right)$. From Fig. 6(a), a $\mathrm{N}_{\text {eff }}$ annealing rate of around $2 \times 10^{11} / \mathrm{cm}^{2}$ per decade of time at $200 \circ \mathrm{C}$ can be estimated. Hydrogen release from the layers could lead to reduction of negative charges at the silicon/dielectric interface for these $\mathrm{O}_{3}$-grown $\mathrm{Al}_{2} \mathrm{O}_{3}$ layers. $\mathrm{A}$ similar logarithmic dependence has been encountered for example in bias temperature instabilities (BTI) $[54,55]$ or when studying detrapping characteristics of negatively charged $\mathrm{Si}_{3} \mathrm{~N}_{4}$ layers for silicon solar cells passivation, exposed to similar temperatures in the range of $100^{\circ} \mathrm{C}$ to $200 \div \mathrm{C}[56]$.

Figure 6(b) shows the effective trapped charge densities obtained for some non-irradiated and gamma irradiated $40 \mathrm{~nm} \mathrm{NRL} \mathrm{Al}_{2} \mathrm{O}_{3} \mathrm{MOS}$ capacitors exposed to different temperatures between $100^{\circ} \mathrm{C}$ and $200^{\circ} \mathrm{C}$. From the figure, a good thermal stability of the original $\mathrm{Al}_{2} \mathrm{O}_{3}$ negative charges is also observed under a $100^{\circ} \mathrm{C}$ thermal treatment. However, a comparable removal of effective negative charges is also appreciated for these NRL layers subjected to 
higher temperatures $\left(175^{\circ} \mathrm{C}\right.$ and $\left.200^{\circ} \mathrm{C}\right)$. In this case, however, the trend is better fitted by a second order logarithmic dependence on annealing time. The existence of possible competing mechanisms, like hydrogen release from the interface and detrapping of negative charges in these $\mathrm{H}_{2} \mathrm{O}$-grown $\mathrm{Al}_{2} \mathrm{O}_{3}$ layers, might be responsible for the $\mathrm{N}_{\text {eff }}$ versus annealing time curves obtained for 30 Mrad gamma-irradiated 40nm NRL PMA MOS capacitors in Fig. 6(b).

\section{CONCLUSIONS}

In order to investigate the electrical properties and radiation hardness of $\mathrm{ALD} \mathrm{Al}_{2} \mathrm{O}_{3}$ layers to be used as passivation films for silicon radiation detectors with slim edges, MOS capacitors implementing differently processed $\mathrm{Al}_{2} \mathrm{O}_{3}$ layers have been fabricated on p-type silicon substrates. An extensive capacitance-voltage and current-voltage characterization has been carried out. The effects of gamma and proton irradiations, up to equivalent doses of 30 Mrad and 21.07 Mrad, respectively, have been studied. Qualitatively similar results are obtained for device degradation under equivalent doses of gamma and proton irradiations. While similar negative charge densities are initially encountered for all non-irradiated MOS structures, higher radiation resistance is observed for capacitors with $\mathrm{Al}_{2} \mathrm{O}_{3}$ layers grown with $\mathrm{H}_{2} \mathrm{O}$ instead of $\mathrm{O}_{3}$ as oxidant precursor. Competing effects between radiation-induced positive charge trapping and hydrogen release from the $\mathrm{H}_{2} \mathrm{O}$-grown $\mathrm{Al}_{2} \mathrm{O}_{3}$ layers may explain their superior radiation hardness. Importantly for envisaged applications, negatively charged dielectric layers are still obtained for some of the most irradiated samples. Finally, the thermal stability of the electrical characteristics of irradiated and non-irradiated MOS 
capacitors with differently processed $\mathrm{Al}_{2} \mathrm{O}_{3}$ layers has been evaluated by means of annealing treatments in air at temperatures ranging from $100^{\circ} \mathrm{C}$ to $200^{\circ} \mathrm{C}$. A significant recovery of the gamma-radiation-induced damage affecting the electrical characteristics of $\mathrm{O}_{3}$-grown $\mathrm{Al}_{2} \mathrm{O}_{3}$ layers has been observed. This can be explained by a trapped holes thermal emission process, for which an activation energy of $1.38 \pm 0.15 \mathrm{eV}$ has been extracted.

\section{Acknowledgements}

This work has been performed within the framework of CERN RD50 Collaboration and ATLAS Planar Pixel Proposal. This work has been partially financed by the Spanish Ministry of Education and Science through the Particle Physics National Program FPA2013-48308-C2-2-

P. We would like to thank the Institute for Nanoscience (NSI) at the U.S. Naval Research Laboratory (NRL) and the NSI staff. The work done at NRL was supported by the Chief of Naval Research (CNR). The work at SCIPP was supported by Department of Energy, grant DEFG02-13ER41983. The work at BNL was supported by DOE Contract No. DE-SC0012704. 


\section{References}

[1] Wong $\mathrm{H}$, Iwai $\mathrm{H}$. On the scaling issues and high-k replacement of ultrathin gate dielectrics for nanoscale MOS transistors. Microelectron Eng 2006;83:1867-904.

[2] Robertson J. High dielectric constant gate oxides for metal oxide Si transistors. Rep Prog Phys 2006;69:327-96.

[3] Hoex B, Schmidt J, Pohl P, Van de Sanden MCM, Kessels WMM. Silicon surface passivation by atomic layer deposited $\mathrm{Al}_{2} \mathrm{O}_{3}$. J Appl Phys 2008;104:044903.

[4] Weber JR, Janotti A, Van de Walle CG. Native defects in $\mathrm{Al}_{2} \mathrm{O}_{3}$ and their impact on III-V/ $\mathrm{Al}_{2} \mathrm{O}_{3}$ metal-oxide-semiconductor-based devices. J Appl Phys 2011;109:033715.

[5] Dingemans $\mathrm{G}$, Kessels WMM. Status and prospects of $\mathrm{Al}_{2} \mathrm{O}_{3}$-based surface passivation schemes for silicon solar cells. J Vac Sci Technol A 2012;30:040802.

[6] Terlinden NM, Dingemans G, Vandalon V, Bosch RHEC, Kessels WMM. Influence of the $\mathrm{SiO}_{2}$ interlayer thickness on the density and polarity of charges in $\mathrm{Si} / \mathrm{SiO}_{2} / \mathrm{Al}_{2} \mathrm{O}_{3}$ stacks as studied by optical second-harmonic generation. J Appl Phys 2014;115:033708.

[7] Hoex B, Heil SBS, Langereis E, Van de Sanden MCM, Kessels WMM. Ultralow surface recombination of c-Si substrates passivated by plasma-assisted atomic layer deposited $\mathrm{Al}_{2} \mathrm{O}_{3}$. Appl Phys Lett 2006;89:042112.

[8] Agostinelli G, Delabie A, Vitanov P, Alexieva Z, Dekkers HFW, De Wolf S, Beaucarne G. Very low surface recombination velocities on $p$-type silicon wafers passivated with a dielectric with fixed negative charge. Sol Energ Mat Sol C 2006;90:3438-43.

[9] Casse G, Allport PP, Greenall A. Response to minimum ionising particles of p-type substrate silicon microstrip detectors irradiated with neutrons to LHC upgrade doses. Nucl Instr Meth A 2007;581:318-21.

[10] Hara K, Affolder AA, Allport PP, Bates R, Betancourt C, Bohm J, et al. Testing of bulk radiation damage of $n$-in-p silicon sensors for very high radiation environments. Nucl Instr Meth A 2011;636:S83-9.

[11] www.cern.ch/atlas 
[12] Fadeyev V, Sadrozinski HF-W, Ely S, Wright JG, Christophersen M, Phlips BF, et al. Scribe-cleave-passivate (SCP) slim edge technology for silicon sensors. Nucl Instr Meth A 2013;731:260-5.

[13] Christophersen M, Fadeyev V, Ely S, Phlips BF, Sadrozinski HF-W. The effect of different dicing methods on the leakage currents of $n$-type silicon diodes and strip sensors. Solid-State Electron 2013;81:8-12.

[14] Christophersen M, Fadeyev V, Phlips BF, Sadrozinski HF-W. Scribing-cleavingpassivation for high energy physics silicon sensors. Proceedings of Science (Vertex 2012) 2013;20.

[15] Christophersen M, Fadeyev V, Phlips BF, Sadrozinski HF-W, Parker C, Ely S, Wright JG. Alumina and silicon oxide/nitride sidewall passivation for $p$ - and $n$-type sensors. Nucl Instr Meth A 2011;699:14-7.

[16] Unno Y, Ikegami Y, Terada S, Mitsui S, Jinnouchi O, Kamada S, Yamamura K, et al. Development of $n$-in-p silicon planar pixel sensors and flip-chip modules for very high radiation environments. Nucl Instr Meth A 2011;650:129-35.

[17] Fadeyev V, Ely S, Galloway Z, Ngo J, Parker C, Sadrozinski HF-W, et al. Update on scribe-cleave-passivate (SCP) slim edge technology for silicon sensors: automated processing and radiation resistance. Nucl Instr Meth A 2014;765:59-63.

[18] Ribes G, Mitard J, Denais M, Bruyere S, Monsieur F, Parthasarathy C, Vincent E, Ghibaudo G. Review on high-k dielectrics reliability issues. IEEE T Device Mat Re 2005;5:5-19.

[19] Felix JA, Schwank JR, Fleetwood DM, Shaneyfelt MR, Gusev EP. Effects of radiation and charge trapping on the reliability of high-k gate dielectrics. Microelectron Reliab 2004;44:563-75.

[20] Choi BK, Fleetwood DM, Massengill LW, Schrimpf RD, Galloway KF, Shaneyfelt MR, Meisenheimer TL, Dodd PE, Schwank JR, Lee YM, Johnson RS, Lucovsky G. Reliability degradation of ultra-thin oxynitride and $\mathrm{Al}_{2} \mathrm{O}_{3}$ gate dielectric films owing to heavy-ion irradiation. Electron Lett 2002;38:157-8. 
[21] Rafí JM, Campabadal F, Ohyama H, Takakura K, Tsunoda I, Zabala M, Beldarrain O, González MB, García H, Castán H, Gómez A, Dueñas S. 2 MeV electron irradiation effects on the electrical characteristics of metal-oxide-silicon capacitors with atomic layer deposited $\mathrm{Al}_{2} \mathrm{O}_{3}, \mathrm{HfO}_{2}$ and nanolaminated dielectrics. Solid-State Electron 2013;79:65-74.

[22] Rafí JM, González MB, Takakura K, Tsunoda I, Yoneoka M, Beldarrain O, Zabala M, Campabadal F. $2 \mathrm{MeV}$ electron irradiation effects on the electrical characteristics of MOS capacitors with $\mathrm{ALD} \mathrm{Al}{ }_{2} \mathrm{O}_{3}$ dielectrics of different thickness. Microelectron Reliab 2013;53:1333-7.

[23] Felix JA, Shaneyfelt MR, Fleetwood DM, Schwank JR, Dodd PE, Gusev EP, Fleming RM, D’Emic C. Charge trapping and annealing in high-k gate dielectrics. IEEE T Nucl Sci 2004;51:3143-9.

[24] Vermang B, Goverde H, Uruena A, Lorenz A, Cornagliotti E, Rothschild A, John J, Poortmans J, Mertens $\mathrm{R}$. Blistering in $\mathrm{ALD} \mathrm{Al}_{2} \mathrm{O}_{3}$ passivation layers as rear contacting for local AI BSF Si solar cells. Sol Energ Mat Sol C 2012;101:204-9.

[25] Beldarrain O, Duch M, Zabala M, Rafí JM, González MB, Campabadal F. Blistering of atomic layer deposition $\mathrm{Al}_{2} \mathrm{O}_{3}$ layers grown on silicon and its effect on metal-insulatorsemiconductor structures. J Vac Sci Technol A 2013;31:01A128.

[26] Berger MJ, Coursey JS, Zucker MA, Chang J. ESTAR, PSTAR, and ASTAR: Computer Programs for Calculating Stopping-Power and Range Tables for Electrons, Protons, and Helium lons, version 1.2.3. National Institute of Standards and Technology, Gaithersburg, MD; 2005. Available online: http://physics.nist.gov/Star (accessed on 2 October 2015).

[27] Schroder DK. Semiconductor Material and Device Characterization. New York: John Wiley \& Sons; 1990, p. 276.

[28] Carter RJ, Cartier E, Kerber A, Pantisano L, Schram T, De Gendt S, Heyns M. Passivation and interface state density of $\mathrm{SiO}_{2} / \mathrm{HfO}_{2}$-based/polycrystalline-Si gate stacks. Appl Phys Lett 2003;83:533-5.

[29] Fleetwood DM. “Border traps" in MOS devices. IEEE T Nucl Sci 1992;39:269-71. 
[30] Kerber A, Cartier E, Pantisano L, Degraeve R, Kauerauf T, Kim Y, et al. Origin of the threshold voltage instability in $\mathrm{SiO}_{2} / \mathrm{HfO}_{2}$ dual layer gate dielectrics. IEEE Electr Device L 2003;24:87-9.

[31] Campabadal F, Beldarrain O, Zabala M, Acero MC, Rafí JM. Comparison between $\mathrm{Al}_{2} \mathrm{O}_{3}$ thin films grown by ALD using $\mathrm{H}_{2} \mathrm{O}$ or $\mathrm{O}_{3}$ as oxidant source. In: Proceedings of the 2011 Spanish conference on electron devices (CDE), Palma de Mallorca, Spain; 2011. doi: 10.1109/SCED.2011.5744238

[32] Oh S-K, Shin H-S, Jeong K-S, Li M, Lee H, Han K, Lee Y, Lee G-W, Lee H-D. Process temperature dependence of $\mathrm{Al}_{2} \mathrm{O}_{3}$ film deposited by thermal $\mathrm{ALD}$ as a passivation layer for c-Si solar cells. J Semicond Tech Sci 2013;13:581-8.

[33] Rafí JM, Zabala M, Beldarrain O, Campabadal F. Deposition temperature and thermal annealing effects on the electrical characteristics of atomic layer deposited $\mathrm{Al}_{2} \mathrm{O}_{3}$ films on silicon. J Electrochem Soc 2011;158:G108-14.

[34] Simoen E, Rothschild A, Vermang B, Poortmans J, Mertens R. Impact of forming gas annealing and firing on the $\mathrm{Al}_{2} \mathrm{O}_{3} / \mathrm{p}$-Si interface state spectrum. Electrochem Solid St Lett 2011;14:H362-4.

[35] Kim SK, Lee SW, Hwang CS, Min Y-S, Won JY, Jeong J. Low temperature $(<100 \circ C)$ deposition of aluminum oxide thin films by ALD with $\mathrm{O}_{3}$ as oxidant. J Electrochem Soc 2006;153:F69-76.

[36] Dingemans G, Terlinden NM, Pierreux D, Profijt HB, Van de Sanden MCM, Kessels WMM. Influence of the oxidant on the chemical and field-effect passivation of Si by ALD $\mathrm{Al}_{2} \mathrm{O}_{3}$. Electrochem Solid St Lett 2011;14:H1-4.

[37] Xia Z, Dong J, Li X, Ren C, Sidhu R, Song W, Tao L, Yang Z, Zhang B, Xing G. Comparison between passivation properties of thermal $A L D ~ A{ }_{2} \mathrm{O}_{3}$ deposited with $\mathrm{TMA}+\mathrm{O}_{3}$ and $\mathrm{TMA}+\mathrm{H}_{2} \mathrm{O}$. In: Proceedings of $38^{\text {th }}$ IEEE Photovoltaic Specialists Conference (PVSC), Austin, TX, USA, 3-8 June 2012, p. 1163-5.

[38] Dingemans G, Beyer W, Van de Sanden MCM, Kessels WMM. Hydrogen induced passivation of $\mathrm{Si}$ interfaces by $\mathrm{Al}_{2} \mathrm{O}_{3}$ films and $\mathrm{SiO}_{2} / \mathrm{Al}_{2} \mathrm{O}_{3}$ stacks. Appl Phys Lett 2010;97:152106. 


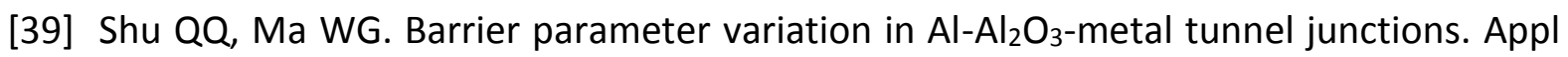
Phys Lett 1992;61:2542-4.

[40] Groner MD, Elam JW, Fabreguette FH, George SM. Electrical characterization of thin $\mathrm{Al}_{2} \mathrm{O}_{3}$ films grown by atomic layer deposition on silicon and various metal substrates. Thin Solid Films 2002;413:186-97.

[41] Chang Y, Ducroquet F, Gautier E, Renault O, Legrand J, Damlencourt JF, Martin F. Surface preparation and post thermal treatment effects on interface properties of thin $\mathrm{Al}_{2} \mathrm{O}_{3}$ deposited by ALD. Microelectron Eng 2004;72:326-31.

[42] Gómez A, Castán H, García H, Dueñas S, Bailón L, Campabadal F, et al. Electrical characterization of high-k based metal-insulator-semiconductor structures with negative resistance effect when using $\mathrm{Al}_{2} \mathrm{O}_{3}$ and nanolaminated films deposited on $\mathrm{p}$ Si. J Vac Sci Technol B 2011;29:01A9011-5.

[43] Schroder DK. Electrical characterization of defects in gate dielectrics. In: Fleetwood DM, Pantelides ST, Schrimpf RD, editors. Defects in Microelectronic Materials and Devices, Boca Raton (FL, USA): CRC Press; 2009, p. 123.

[44] Felix JA, Shaneyfelt MR, Fleetwood DM, Meisenheimer TL, Schwank JR, Schrimpf RD, Dodd PE, Gusev EP, D’Emic C. Radiation-induced charge trapping in thin $\mathrm{Al}_{2} \mathrm{O}_{3} / \mathrm{SiO}_{x} \mathrm{~N}_{\mathrm{y}} / \mathrm{Si}(100)$ gate dielectric stacks. IEEE T Nucl Sci 2003;50:1910-8.

[45] Crook D, Domnitei M, Webb M, Bonini J. Evaluation of modern gate oxide technologies to process charging. In: Proceedings of $31^{\text {st }}$ International Reliability Physics Symposium, Atlanta, USA, 23-25 March 1993, p. 255-61.

[46] Scarpa A, Paccagnella A, Montera F, Ghibaudo G, Pananakakis G, Ghidini G, Fuochi PG. lonizing radiation induced leakage current on ultra-thin gate oxides. IEEE T Nucl Sci $1997 ; 44: 1818-25$

[47] Rafí JM, Vergnet B, Campabadal F, Fleta C, Fonseca L, Lozano M, Martínez C, Ullán M. Electrical characteristics of high-energy proton irradiated ultra-thin gate oxides. Microelectron Reliab 2002;42:1501-4.

[48] Oldham TR, McLean FB. Total ionizing dose effects in MOS oxides and devices. IEEE T Nucl Sci 2003;50:483-99. 
[49] Gielis JJH, Hoex B, van de Sanden MCM, Kessels WMM. Negative charge and charging dynamics in $\mathrm{Al}_{2} \mathrm{O}_{3}$ films on $\mathrm{Si}$ characterized by second-harmonic generation. J Appl Phys 2008;104:073701.

[50] Liao B, Stangl R, Mueller T, Lin F, Bhatia CS, Hoex B. The effect of light soaking on crystalline silicon surface passivation by atomic layer deposited $\mathrm{Al}_{2} \mathrm{O}_{3}$. J Appl Phys 2013;113:024509.

[51] McWhorter PJ, Miller SL, Miller WM. Modeling the anneal of radiation-induced trapped holes in a varying thermal environment. IEEE T Nucl Sci 1990;37:1682-9.

[52] Schwank JR, Winokur PS, McWhorter PJ, Sexton FW, Dressendorfer PV, Turpin DC. Physical mechanisms contributing to device "rebound". IEEE T Nucl Sci 1984;NS31:1434-8.

[53] Riess P, Ceschia M, Paccagnella A, Ghibaudo G, Pananakakis. Comparison of the electrical and thermal stability of stress- or radiation-induced leakage current in thin oxides. Appl Phys Lett 2000;76:1158-60.

[54] Shanware A, Visokay MR, Chambers JJ, Rotondaro ALP, Bu H, Bevan MJ, Khamankar R, Aur S, Nicollian PE, McPherson J, Colombo L. Evaluation of the positive biased temperature stress stability in HfSiON gate dielectrics. In: Proceedings of $41^{\text {st }}$ IEEE International Reliability Physics Symposium (IRPS), Dallas, TX, USA, 30 March-4 April 2003, p. 208-13.

[55] Grasser T, Kaczer B. Evidence that two tightly coupled mechanisms are responsible for negative bias temperature instability in oxynitride MOSFETs. IEEE T Electron Dev 2009;56:1056-62.

[56] Ren Y, Nursam NM, Wang D, Weber KJ. Charge stability in LPCVD silicon nitride for surface passivation of silicon solar cells. In: Proceedings of $35^{\text {th }}$ IEEE Photovoltaic Specialists Conference (PVSC), Honolulu, HI, USA, 20-25 June 2010, p. 897-901. 


\section{TABLE CAPTIONS}

Table 1: $\mathrm{Al}_{2} \mathrm{O}_{3}$ deposition conditions and measured thickness (ellipsometrically and interferometrically) for the four fabricated silicon wafers with MOS capacitors.

Table 2: Electrical parameters extracted from the $C-V$ characterization and from the dielectric breakdown statistics for different sets of 25 MOS capacitors corresponding to the four fabricated wafers with and without postmetallization annealing. Mean values and corresponding standard deviations are given for the main $\mathrm{C}-\mathrm{V}$ parameters.

\section{FIGURE CAPTIONS}

Figure 1: Capacitance-voltage characteristics measured from inversion to accumulation and accumulation to inversion voltage sweeps for $\mathrm{Al}_{2} \mathrm{O}_{3} \mathrm{MOS}$ capacitors corresponding to the four fabricated wafers with and without postmetallization annealing. Some peaks in the corresponding conductance characteristics measured from inversion to accumulation can be appreciated in the inset. 
Figure 2: Current density versus applied voltage measured for $\mathrm{Al}_{2} \mathrm{O}_{3} \mathrm{MOS}$ capacitors corresponding to the four fabricated wafers with and without postmetallization annealing. The round symbols correspond to Fowler-Nordheim conduction fits.

Figure 3: (a) Capacitance-voltage characteristics measured from inversion to accumulation and accumulation to inversion for $40 \mathrm{~nm} \mathrm{CNM} \mathrm{Al} \mathrm{O}_{3} \mathrm{MOS}$ capacitors. The different curves correspond to non-irradiated and gamma irradiated devices at different doses. (b) Effective trapped charges densities extracted from C-V characteristics of MOS capacitors as a function of gamma and proton irradiation dose.

Figure 4: (a) Current density versus applied voltage measured on non-irradiated and gamma irradiated $40 \mathrm{~nm} \mathrm{CNM} \mathrm{Al}{ }_{2} \mathrm{O}_{3}$ MOS capacitors. (b) Radiation-induced voltage shift of the current voltage characteristics at a fixed current density level of $5 \times 10^{-7} \mathrm{~A} / \mathrm{cm}^{2}$ as a function of gamma and proton irradiation dose. 
Figure 5: Effective trapped charge densities as a function of thermal annealing time for some (a) gamma irradiated and (b) proton irradiated $40 \mathrm{~nm} \mathrm{CNM} \mathrm{Al} 2 \mathrm{O}_{3} \mathrm{MOS}$ capacitors exposed to different temperatures. The lines correspond to logarithmic fits. The inset in (a) shows the required time to anneal a fixed percentage (30\%) of $\mathrm{N}_{\text {eff }}$ degradation as a function of the inverse of annealing temperature, evidencing an Arrhenius-law dependency with extracted activation energy of $1.38 \pm 0.15 \mathrm{eV}$.

Figure 6: Effective trapped charge densities as a function of thermal annealing time for some (a) non-irradiated $40 \mathrm{~nm} \mathrm{CNM} \mathrm{Al} \mathrm{O}_{3} \mathrm{MOS}$ capacitors and (b) nonirradiated and gamma irradiated $40 \mathrm{~nm} \mathrm{NRL} \mathrm{Al}_{2} \mathrm{O}_{3} \mathrm{MOS}$ capacitors exposed to different temperatures between $100^{\circ} \mathrm{C}$ and $200^{\circ} \mathrm{C}$. The lines in (a) and (b) correspond to first and second order logarithmic fits, respectively, and they are provided as a guide to the eye. 


\begin{tabular}{lcccccc} 
Wafer & $\begin{array}{c}\text { ALD } \\
\text { facility }\end{array}$ & $\begin{array}{c}\text { ALD } \\
\text { ToC }\end{array}$ & $\begin{array}{c}\text { ALD } \\
\text { precursors }\end{array}$ & $\begin{array}{c}\text { PDA } \\
\text { ToC }\end{array}$ & $\begin{array}{c}\mathbf{A l}_{2} \mathbf{O}_{3} \text { thickness } \\
\text { ellipsometry } \\
\text { [nm] }\end{array}$ & $\begin{array}{c}\mathbf{A l}_{2} \mathbf{O}_{3} \text { thickness } \\
\text { interferometry } \\
\text { [nm] }\end{array}$ \\
\hline $40 \mathrm{~nm} \mathrm{CNM}$ & $\mathrm{CNM}$ & 250 & $\mathrm{TMA}^{2} \mathrm{O}_{3}$ & $\mathrm{No}$ & $39.4 \pm 0.2$ & $39.2 \pm 0.2$ \\
$20 \mathrm{~nm} \mathrm{CNM}$ & $\mathrm{CNM}$ & 250 & $\mathrm{TMA}+\mathrm{O}_{3}$ & $\mathrm{No}$ & $20.8 \pm 0.1$ & $20.3 \pm 0.3$ \\
$40 \mathrm{~nm} \mathrm{NRL}$ & $\mathrm{NRL}$ & 300 & $\mathrm{TMA}+\mathrm{H}_{2} \mathrm{O}$ & 300 & Not measured & $41.1 \pm 0.5$ \\
$20 \mathrm{~nm} \mathrm{NRL}$ & $\mathrm{NRL}$ & 300 & $\mathrm{TMA}+\mathrm{H}_{2} \mathrm{O}$ & 300 & Not measured & $21.9 \pm 0.5$
\end{tabular}

Table 1 


\begin{tabular}{lccccccc}
\multicolumn{1}{c}{ Wafer } & $\begin{array}{c}\text { EOT } \\
{[\mathbf{n m}]}\end{array}$ & $\begin{array}{c}\mathbf{V}_{\text {fb }} \\
{[\mathbf{V}]}\end{array}$ & $\begin{array}{c}\mathbf{N}_{\text {eff }} \\
{\left[\times \mathbf{1 0}^{\mathbf{1 2}} \mathbf{c m}^{-\mathbf{2}}\right]}\end{array}$ & $\begin{array}{c}\mathbf{V}_{\text {hys }} \\
{[\mathbf{m V}]}\end{array}$ & $\begin{array}{c}\mathbf{D}_{\text {it }} \\
{\left[\mathbf{c m}^{-2} \cdot \mathbf{e V}^{-1}\right]}\end{array}$ & $\begin{array}{c}\boldsymbol{\alpha} \\
{[\mathbf{V}]}\end{array}$ & $\boldsymbol{\beta}$ \\
\hline $40 \mathrm{~nm}$ CNM PMA & $19.48 \pm 0.14$ & $0.42 \pm 0.03$ & $-1.41 \pm 0.03$ & $95 \pm 12$ & $0.06 \times 10^{12}$ & 34.27 & 7.24 \\
$40 \mathrm{~nm}$ CNM NoPMA & $19.76 \pm 0.10$ & $1.45 \pm 0.35$ & $-2.52 \pm 0.39$ & $150 \pm 32$ & $0.96 \times 10^{12}$ & 33.38 & 12.30 \\
$20 \mathrm{~nm}$ CNM PMA & $10.65 \pm 0.03$ & $-0.15 \pm 0.02$ & $-1.44 \pm 0.05$ & $21 \pm 9$ & $0.06 \times 10^{12}$ & 17.37 & 22.00 \\
20 nm CNM NoPMA & $10.67 \pm 0.11$ & $1.13 \pm 0.30$ & $-4.02 \pm 0.65$ & $137 \pm 10$ & $2.04 \times 10^{12}$ & 17.31 & 8.94 \\
$40 \mathrm{~nm}$ NRL PMA & $22.23 \pm 0.15$ & $0.43 \pm 0.07$ & $-1.25 \pm 0.07$ & $29 \pm 7$ & $0.20 \times 10^{12}$ & 38.06 & 11.52 \\
$40 \mathrm{~nm}$ NRL NoPMA & $22.88 \pm 0.11$ & $3.45 \pm 0.18$ & $-4.06 \pm 0.18$ & $79 \pm 24$ & $0.72 \times 10^{12}$ & 39.20 & 10.18 \\
$20 \mathrm{~nm}$ NRL PMA & $12.26 \pm 0.13$ & $-0.15 \pm 0.05$ & $-1.26 \pm 0.09$ & $34 \pm 15$ & $0.24 \times 10^{12}$ & 18.23 & 4.60 \\
$20 \mathrm{~nm}$ NRL NoPMA & $12.30 \pm 0.14$ & $2.24 \pm 0.39$ & $-5.44 \pm 0.73$ & $145 \pm 60$ & $1.71 \times 10^{12}$ & 18.18 & 5.91
\end{tabular}

Table 2 


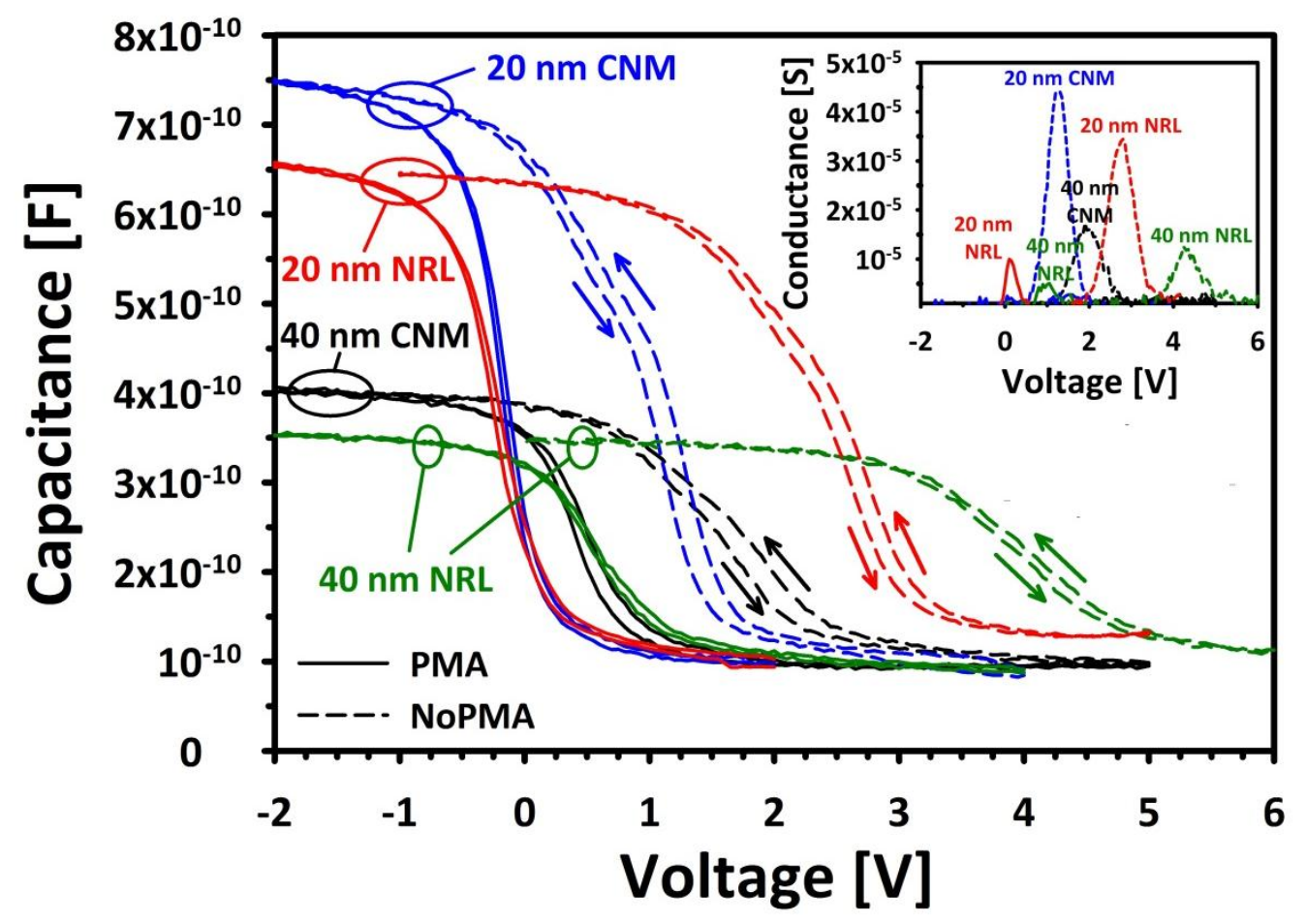

Figure 1 


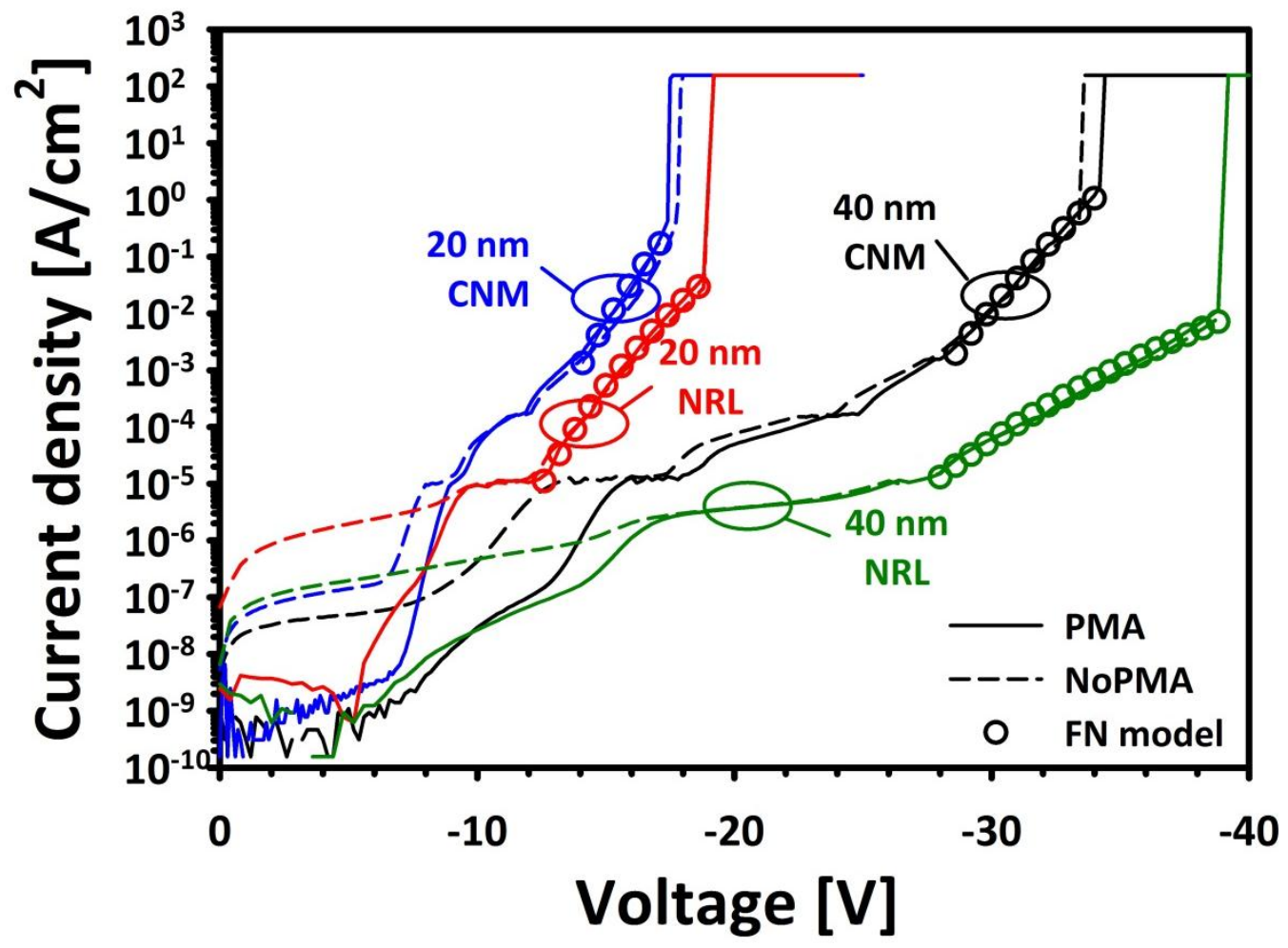

Figure 2 


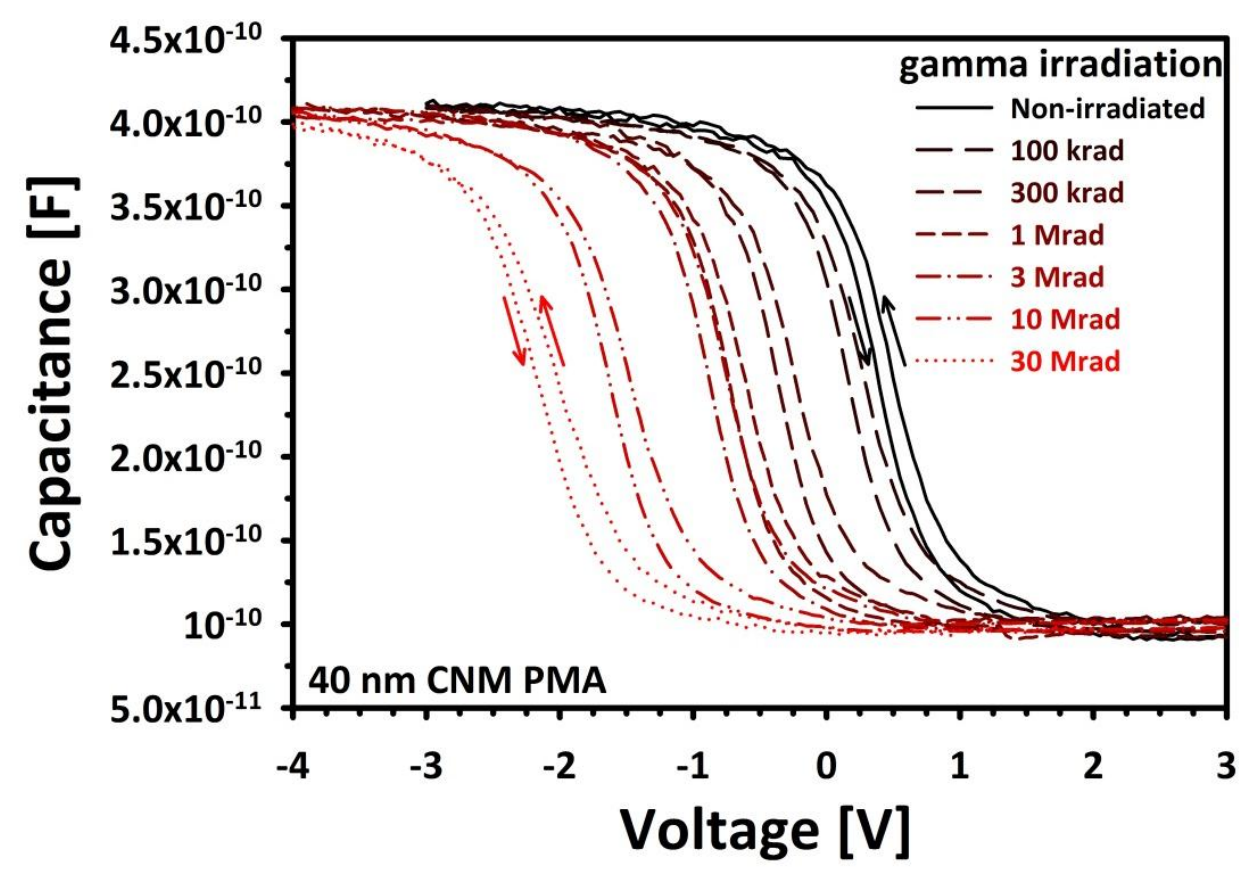

Figure 3(a)

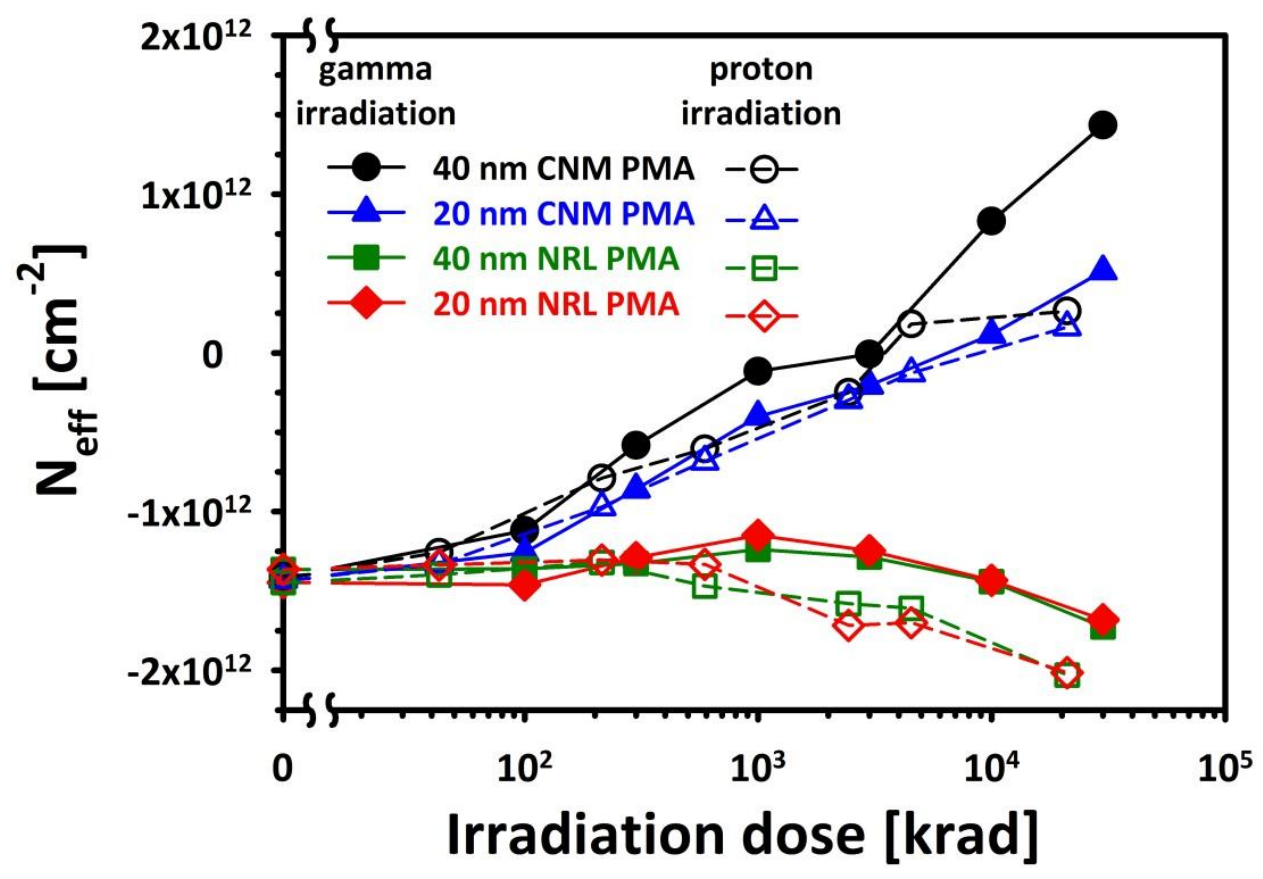

Figure 3(b) 


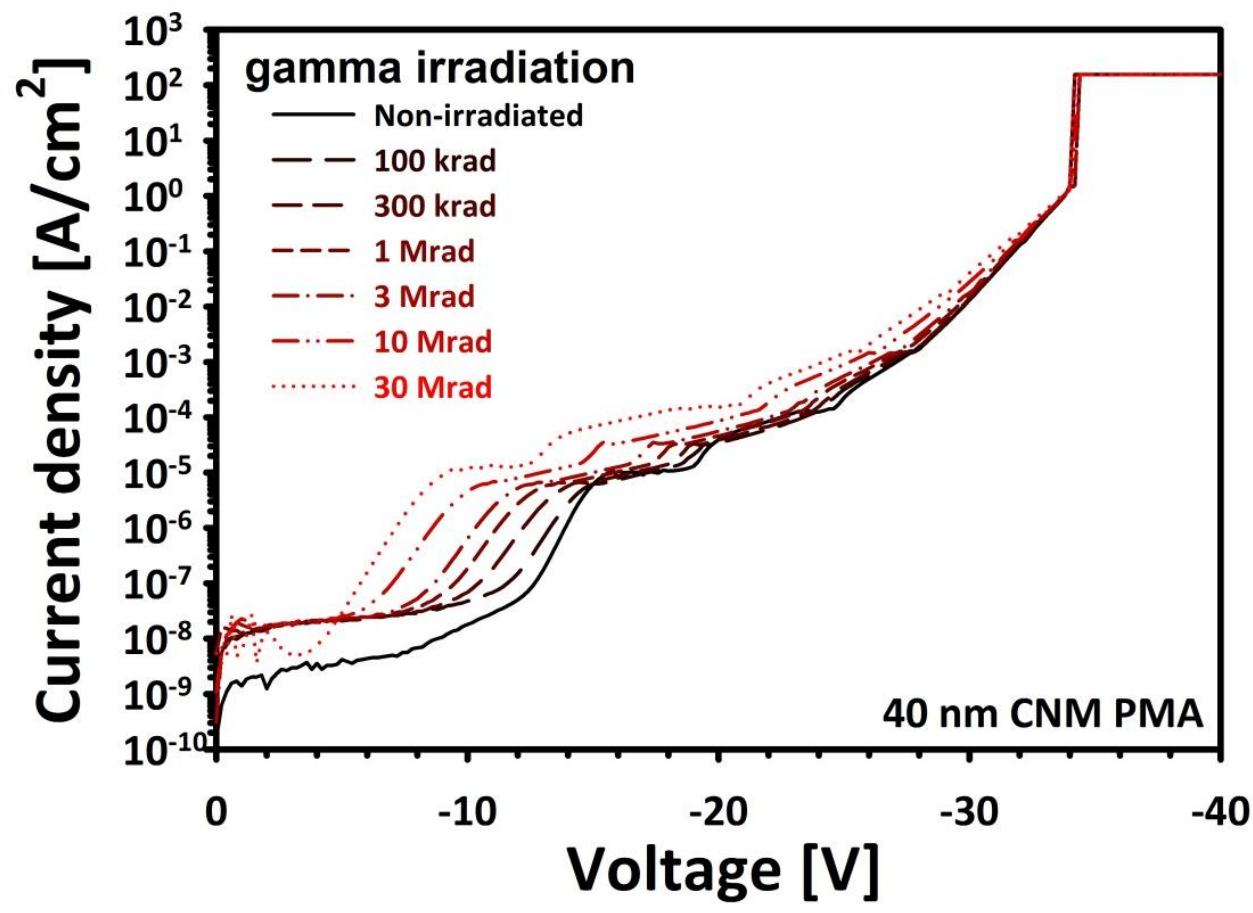

Figure 4(a)

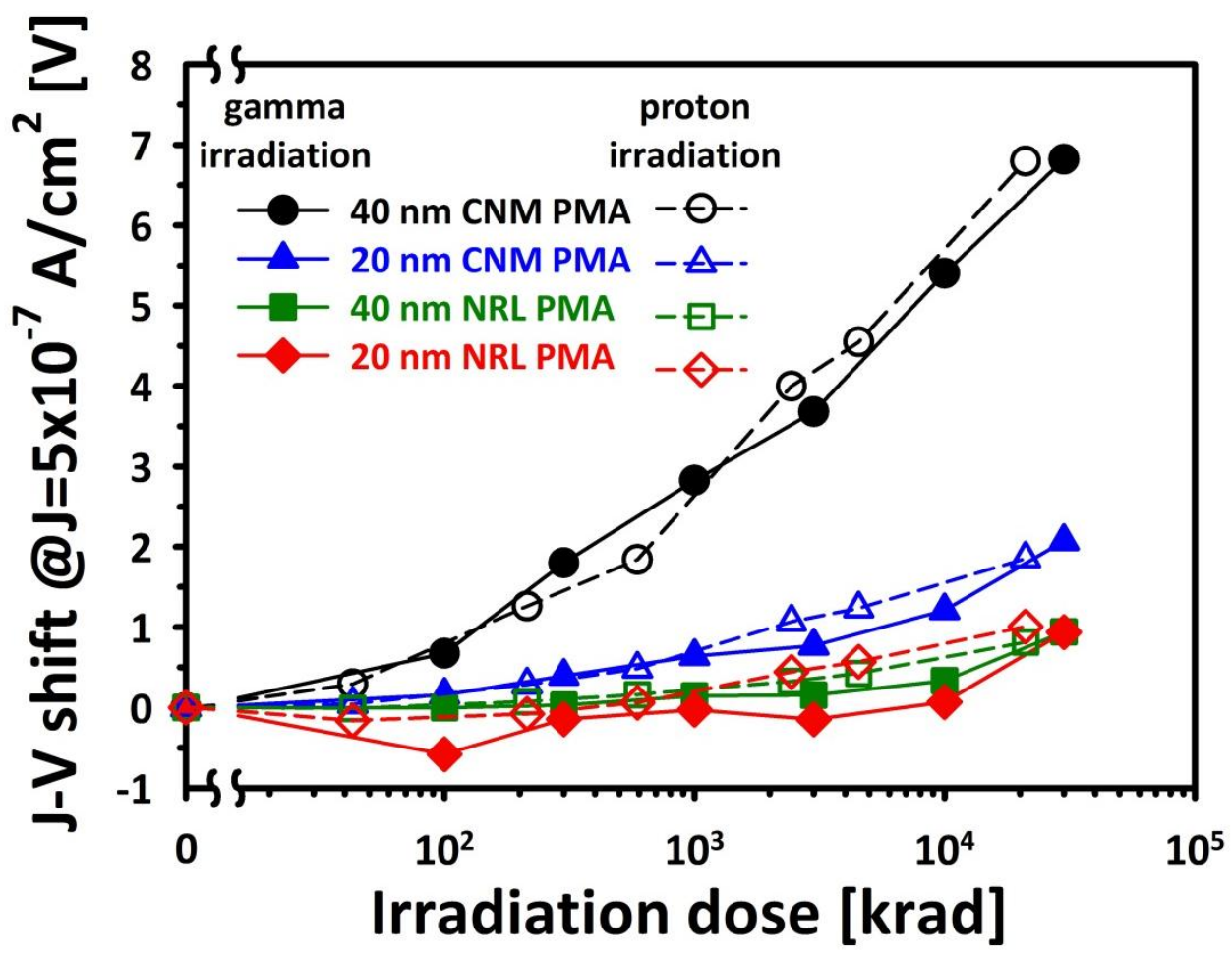

Figure 4(b) 


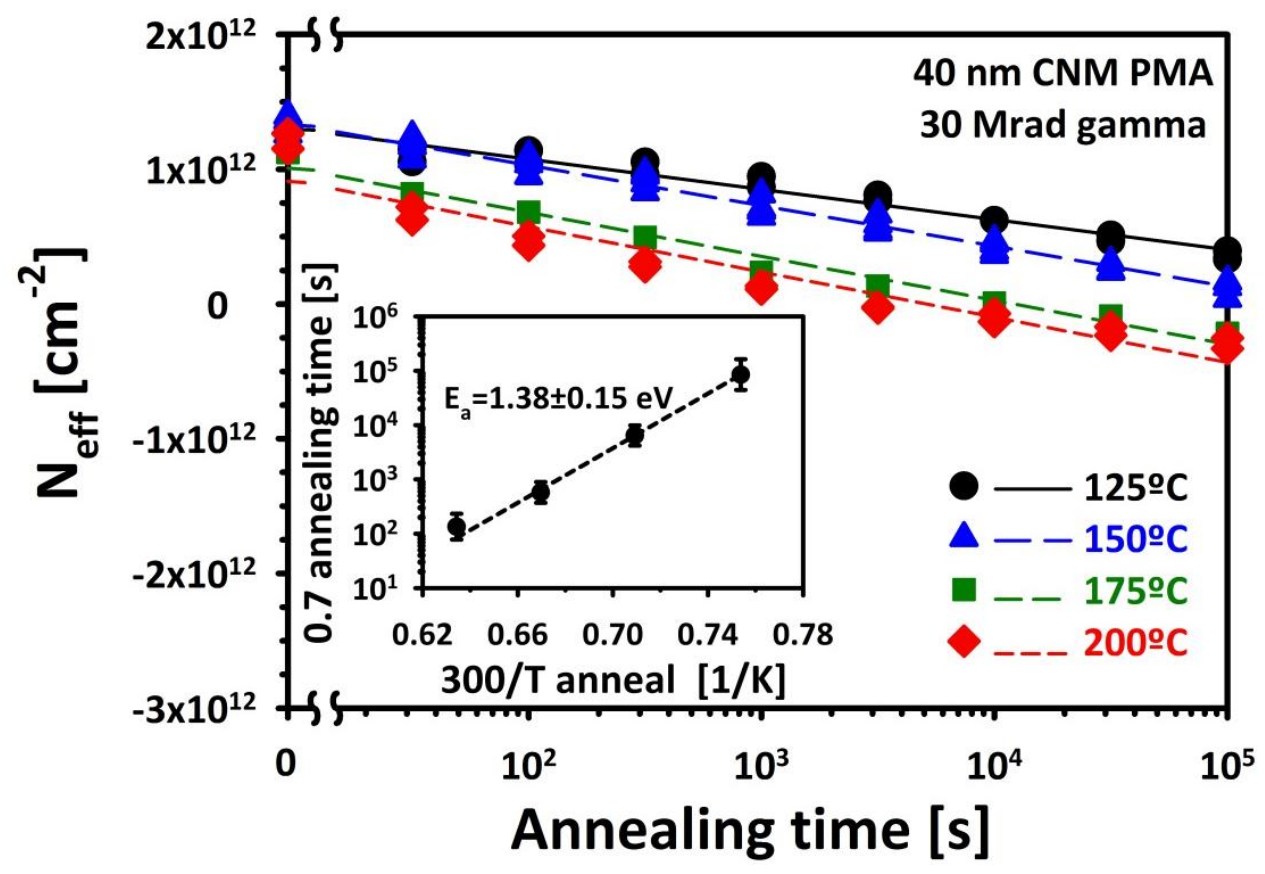

Figure 5(a)

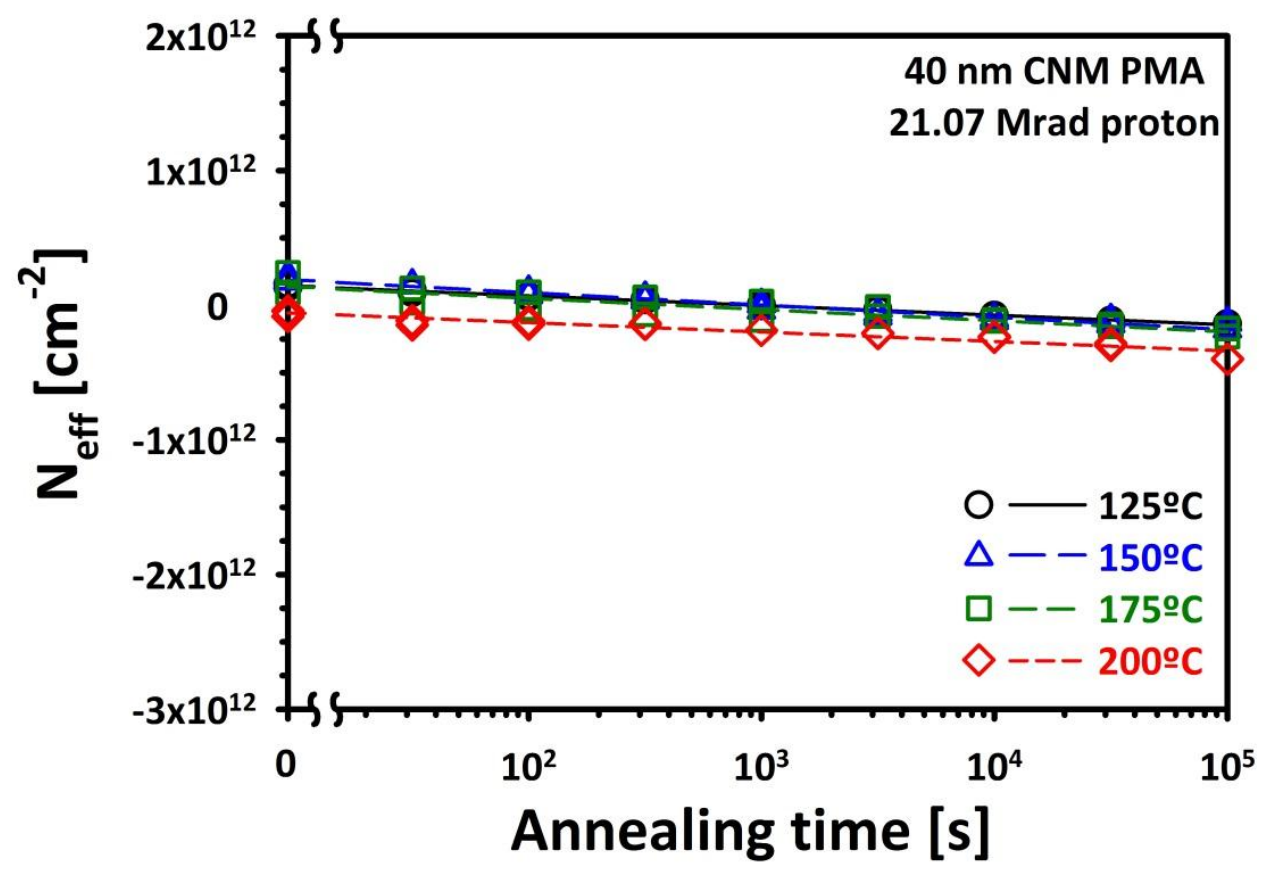

Figure 5(b) 


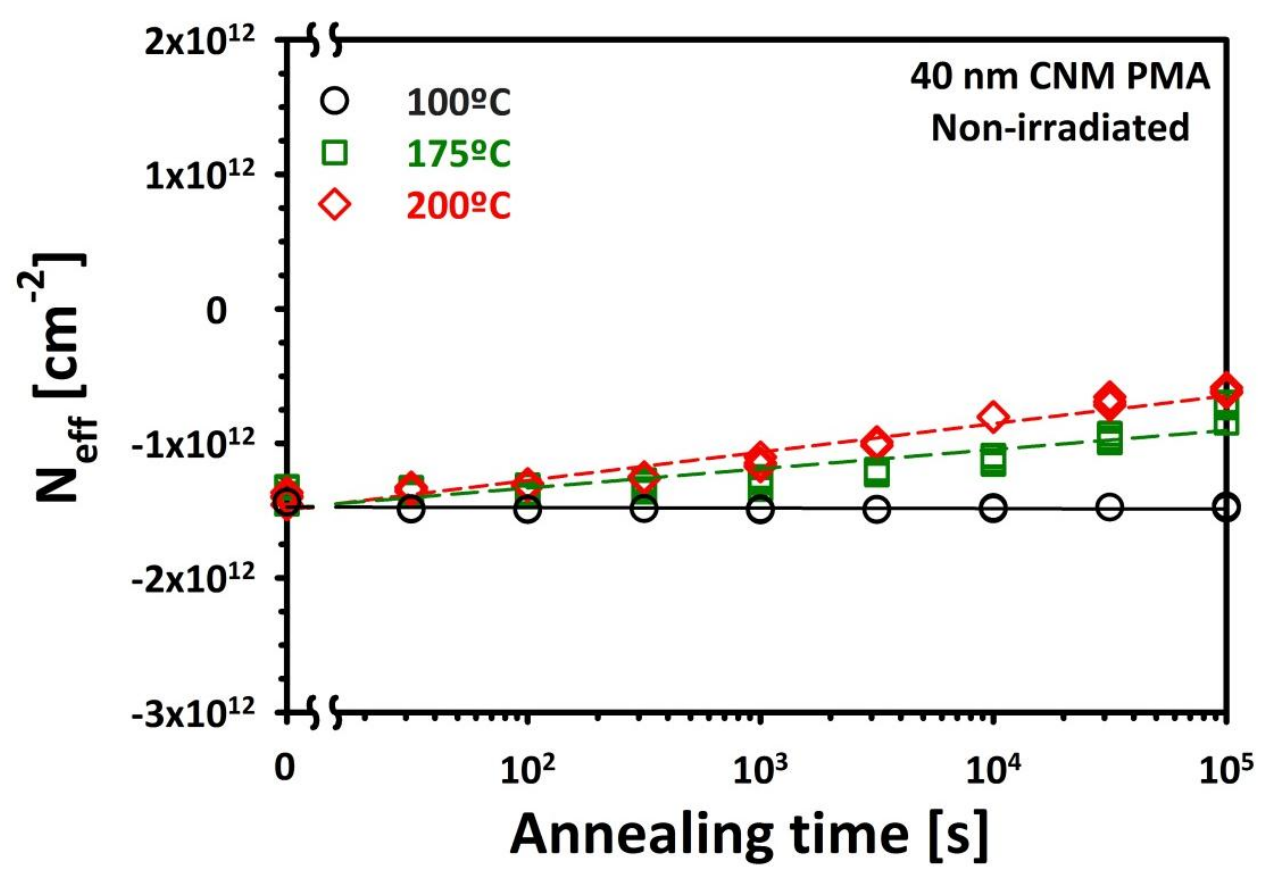

Figure 6(a)

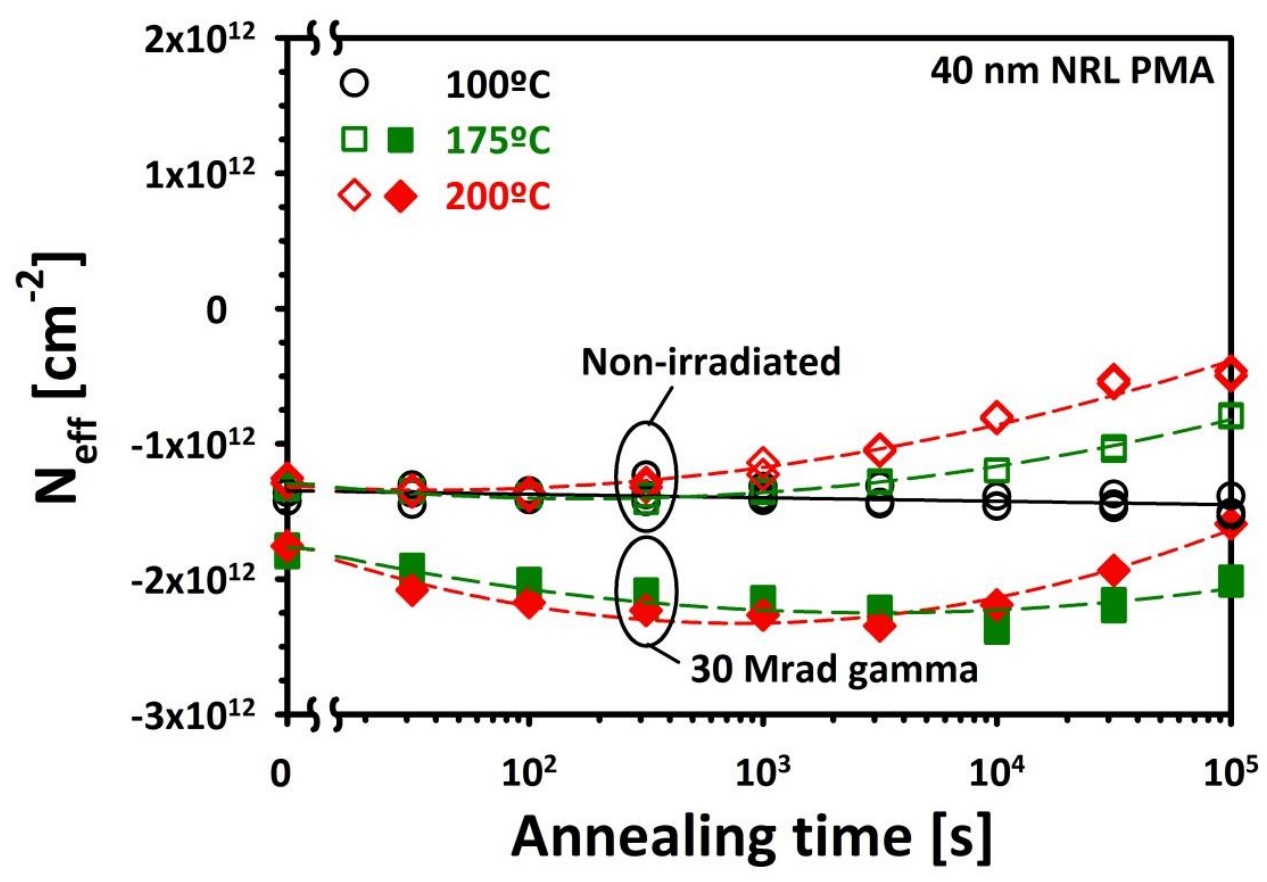

Figure $6(b)$ 